\title{
Measurement of Financial Statements Information in the Context of Harmonization of the Accounting Systems
}

\author{
Irina Golochalova ${ }^{1}$, Viorel Tsurcanu, ${ }^{2, *}$ \\ ${ }^{1}$ Department of Accounting and Economic Informatics, Moldova State University, Chisinau, Republic of Moldova \\ ${ }^{2}$ Department of Accounting, Auditing and Economic Analysis, Academy of Economic Studies of Moldova, Chisinau, Republic of Moldova
}

Email address:

monomah5@yandex.ru (I. Golochalova),vturcanu@mail.ru (V. Tsurcanu)

${ }^{*}$ Corresponding author

\section{To cite this article:}

Irina Golochalova, Viorel Tsurcanu. Measurement of Financial Statements Information in the Context of Harmonization of the Accounting Systems. Journal of Finance and Accounting. Special Issue: Financial Inclusion, Accounting Perspectives and Development. Vol. 8, No. 1, 2020, pp. 48-58. doi: 10.11648/j.jfa.20200801.16

Received: December 19, 2019; Accepted: February 7, 2020; Published: February 18, 2020

\begin{abstract}
The purpose of this study is to establish the ability to assess the quality of financial statements presented by organizations in a particular jurisdiction. The preparation of useful financial statements is possible based on the imperativeness of the concept of qualitative characteristics. An analysis of the composition and grouping of qualitative characteristics outlined in the Conceptual Framework for Financial Reporting, Directive 2013/34/EU and the Law of the Republic of Moldova (RM) "On Accounting and Financial Reporting" made it possible to choose a method for developing a unified methodology for assessing quality of financial reporting in relation to accounting systems, both Anglo-Saxon and continental, as well as individual jurisdictions. A statement of the leading role of reliability and relevance in determining the usefulness of information, while maintaining the value of qualitative characteristics that increase the usefulness of information (in particular, comparability and timeliness), provided the opportunity to build a rational methodology for measuring the quality of financial statements. The proposed methodology is considered as the basis for assessing the quality of reporting, in the framework of which the value of the indicator of useful information is postulated. Based on mathematical modeling, a formula has been developed for calculating the indicator of the usefulness of information, with perfectly prepared financial statements, the value of which is 1 . The use of the method of abstraction and logical thinking allowed us to determine the value of each qualitative characteristic in the quality indicator. It has been established that deviations from this indicator can be the result of either noncompliance with the information quality requirements by the reporting compiler, or ignoring the conceptual platform for presenting useful financial statements. Countries associated with the EU, including the RM, are forced to use a mixed system of accounting and qualitative characteristics (according to International Financial Reporting Standards and Directive 2013/34/EU). The implementation of the recommended methodology for measuring the quality of reporting, using the qualitative characteristics provided for in the legislative framework of the RM, proves the inefficiency of convergence of the two accounting systems in the absence of a special methodology. In general, the study demonstrated that the effective use of the concept of qualitative characteristics: is aimed at promoting the harmonization of accounting systems; serves as a reliable basis for assessing the quality of financial statements; contributes to solving the problem of improving the quality of information in the future.
\end{abstract}

Keywords: Qualitative Characteristics, Concept, Financial Statements, Measurement Model

\section{Introduction}

Information, primarily financial, is the product of a particular accounting system, which is reflected in the financial statements and provides knowledge of the reality surrounding us. Like any product, the information has qualitative characteristics embodied in the system of indexes of financial reports. Based on generally accepted norms, qualitative characteristics should be understood as its properties, therefore reliability, comparability, understandability and others are information properties [1]. 
Each type of qualitative characteristic reflects only one criterion for the measurement of information. However, folded together, the values of all qualitative characteristics can answer the question of information measurement contained in these financial statements.

There are several categories of users, among which investors, creditors, government agencies, management, each of them being interested in some specific information which is valuable for them [2]. Because the users of financial information, especially investors, must make sure that the performance indicators of an economic entity are reliably represented in the financial reports. To do this, they must know the methodology for measuring financial information. It is important that the requirements for the quality of financial information on the activities of economic entities are based on a specific theoretical platform [3]. The documents governing accounting and economic literature are often limited to listing only the qualitative characteristics of financial information, description of their nature and significance. Therefore, the theoretical justification of the qualitative characteristics given in the Conceptual Framework for financial reporting (hereinafter, the IFRS Concept) is necessary. One of the main objectives of the development of accounting at the macro level has been and remains to be its harmonization, which is seen as a process of reducing its differences between individual countries in order to achieve comparability of financial statements of different enterprises [4]. However, various accounting systems prescribe an unequal list of qualitative characteristics. This factor will be taken into account by the authors in developing the measurement methodology.

Since the Anglo-Saxon accounting system is based on IFRS [5] and their Concept [6], the list of qualitative characteristics is taken from these sources, and for the European accounting system from Directive 2013/34/EU of the European Parliament and the Council on annual financial reports, consolidated financial statements and related reports of certain types of enterprises (hereinafter, Directive 2013/34/EU) [7]. Qualitative characteristics approved by a particular country are contained in its legislative and regulatory framework for accounting (laws, standards, regulations), and applied by a separate organization are contained in its accounting policy. At the same time, they have confirmed that the reliable representation of financial information is affected by three main factors: regulatory accounting and reporting in this country; full use of qualitative characteristics of the representation of information; the level of application of professional rationalism of an accountant [8].

In the context of the EU-RM Agreement, Moldova accepted several obligations, including the transfer of the provisions of this directive into its accounting legislation until 2018, which, according to the results of previous reforms, was adapted to the IFRS system. When information of financial statements must be presented outside the country (by joint ventures, companies whose shares are listed on the Stock Exchange), its unification is of particular importance
[9]. In this case, the IFRS Concept provides harmonization of financial statements [10]. The harmonization process is more easily in countries that practice the Anglo-Saxon accounting system, characterized by greater liberalization [11]. In this regard, the authors ask the following questions: Does the Republic of Moldova accounting methodology have a single concept for applying qualitative characteristics that meet the requirement of the reliability of financial statements? Is the model of qualitative characteristics of the financial reporting system of the Republic of Moldova functional for presenting clear information about the financial situation of a business unit and does it mislead users when they make economic decisions?

The answers to these questions lie in the plane of methodological argumentation and evidence. In this context, the authors formulated the following hypotheses are proposed $(\mathrm{H})$ :

H1: in the accounting methodology of the Republic of Moldova, there is no conceptual space for applying qualitative characteristics that meet the requirement of the reliability of financial statements to disorientate users in the process of making economic decisions.

$\mathrm{H} 2$ : the accounting system of the Republic of Moldova has not yet developed a technique for measuring financial statements information, which does not allow the quality control, both from the side of the compiler and from its users.

The objective of this paper is to develop methodology for evaluating the presented information that is acceptable by any accounting system, both at the highest level (AngloSaxon or European) and at the lowest level (business entities of a particular country) based on a logical analysis, understanding the context and significance of each of the qualitative characteristics and their ranking. To achieve this goal, the authors are proposed formulas' and specific calculations, as well as conclusions on the measurement of accounting systems.

\section{Literature Review}

The problem of application of the system of qualitative characteristics of financial reporting has been widely discussed from the perspective of comparing two accounting models, in terms of modernization of the financial statements, from the aspect of the influence of the type of user in determining the quality of information, in the context of the nature of the qualitative characteristics in the IFRS system, their role in the reliability of the financial reporting concept and finally in its adaptation in practice. Some of them have a methodological nature while the goal of others is empirical research.

\subsection{Nature of Methodological}

One of the main questions of theorists of the late 20th century the beginning of the 21 st century, are the differences and the ways of harmonization of the two main accounting systems. The French scientists Colass [11], the English scientist Alexander [12], as well as the Romanian researcher 
Tabara [4], stand out among those theorists who analyzed the influence of principles of accounting system and qualitative characteristics of information on accounting systems and financial statements. The essence of the discussions on this topic is as follows. In the Anglo-American system, the liberal form of registration of economic events, guided by the concept of reliable representation, dominates [12]. This system is based on principles and qualitative characteristics. It leaves more space for accounting judgments in the recording of transactions and when preparing financial statements. Moreover, the countries of the European Union, when registering economic facts, draw more attention to the compliance of legal norms; hence, there is less space left for qualitative characteristics and accounting rationalism $[4,11]$.

Sokolov [13] adheres to the conceptual approach to measuring the quality of financial statements, which considers it as one of the most important accounting problems. According to this scientist, the quality of financial statement does not depend on its possession of certain properties, but on the degree of correlation of two concepts: the concept of reliability (faithfully represented) and the concept of good faith (accuracy). An equal ratio of degrees of concepts is an ideal in which financial statement qualifies as useful for decision-making. The prevalence of the degree of one of the concepts in their ratio is determined by the conscious perceptibility of the preparers of the accounting procedures and economic phenomena, and leads to a decrease in the quality of financial statements and, as a consequence, the level of utility [13]. In this regard, it is appropriate to emphasize that Sokolov's position on determining the quality of financial statements is consistent with the IFRS Concept, according to which the achievement of the usefulness of financial statements based on the prescribed use of qualitative characteristics is an ideal, but one should strive for it [6]. Alexander [12] emphasizes eclecticism in the modern concept of preparing financial statements. He was of the view that this phenomenon is not the result of deliberate development, but the interpenetration of financial reporting theories in the process of harmonizing the accounting system. This scientist also adheres to the point of view on the influence of the behavioral approach in the process of presenting information, which inevitably leads to a decrease in its quality [12]. Attention should be paid to the work of Alekseev, Glinskiy, Serga, Pyatov [14], in which the authors prove that accounting paradoxes a priori lead to distortion of information in financial statements and reduce its reliability. In this study, on the basis of a grouping of accounting paradoxes are used to evaluate the impact of each group of paradoxes on the reliability of financial statements; moreover, a group of users is determined whose decisions are affected by the identified distortions of information.

However, the authors of these scientific works study the problem of measuring the quality of financial statements through the prism of theories of accounting and reporting, while minimizing the importance of the concept of qualitative characteristics. A more detailed analysis of qualitative characteristics is given in the work Tsurcanu and
Golochalova [15]. Based on the IFRS Concept, version of 2010, and accounting systems, they provide a list of qualitative characteristics in accordance with IFRS and Directive 2013/34/EU, and highlight which prevail in each system, paying attention to the principles of reliability and prudence [15]. A separate work by Tsurcanu, Golochalova [8] is devoted to the concept of reliability, which analyzes the factors affecting any accounting system - accountants, accounting technique, qualitative characteristics, entity management, audit control, accounting normalization, and using the example of the Republic Moldova the consequences of non-compliance with the reliability of accounting are shown.

A slightly different point of view is given by Achim and Chis [2], who, through the prism of measuring the quality of financial accounting, examine the role of key characteristics of financial reporting information recognized as qualitative. They believe that the factors that determine the quality of financial accounting, qualified as an effective and useful accounting system, are the legal system, the source of financing, the professional judgment of the compiler and his accounting education, and the development of the economy. According to these researchers, the qualitative characteristics of the financial statement that it should demonstrate - relevance, reliability, and comparability, play a secondary role in this process, since their purpose is only to facilitate the process of economic decision-making [2]. This position is consistent with the trends of the continental accounting system.

Another interesting question at this stage of accounting development is the features of accounting and reporting in countries associated with the EU after the provisions of Directive 2013/34/EU have been transferred into their legislation. Tsurcanu and Golochalova [15] raise the question of what will happen to account in the Republic of Moldova after it approaches the European Directives. The answer is that it will be situated between them and IFRS, proving this, among other things, based on an analysis of accounting principles and the qualitative characteristics of these two systems. However, accounting in such countries as the RM will remain strictly regulated and focused on the legal interpretation of economic phenomenon, and insufficient attention to the qualitative characteristics will be paid [15] Law No. 287 of December 15, 2017 of the RM "On Accounting and Financial reporting" (hereinafter referred to as Law No. 287) confirmed this hypothesis. Here we should not forget about the impact of tax legislation on accounting. On this occasion, Richard [16] successfully commented: "As a result, we get a kind of hybrid..." of accounting.

\subsection{Empirical Nature}

There exist different opinions on the issue of qualitative characteristics. However, it must be noted that Directive 2013/34/ EU also contains requirements about the need to establish the amount of information presented in the financial statements for big, medium, and small enterprises. Back in the late 90s, French authors Bethoux and Kremper [9], for the first time, put forward a thesis on the value of the volume 
(quantity) of information in financial statements and clearly indicated its representation parameters that are necessary for various categories of enterprises.

An integrated approach aimed at developing a system for measurement of the quality of financial statements was used by van Beest, Braam, Boelens [17]. The authors suggested a mechanism for a comprehensive measurement of financial statements based on the qualitative characteristics of IFRS, the use of which allowed them to establish several variables that have a significant impact on the quality of financial information: accounting standards, the legal system, and its effectiveness, size and industry affiliation of a business unit [17]. However, as emphasized by the researchers, the measurement mechanism they created has a limitation: the usefulness of financial reporting information is measured according to the interests of shareholders, investors, or creditors to make economic decisions.

A special attention should be paid to the work of Nobes and Stadler [18], in the framework of which they put forward and proved a hypothesis about the determining influence of changes in accounting policies on qualitative characteristics, and primarily on relevance, faithful representation, comparability and comprehensibility. In the process of compliance with the qualitative characteristics of financial statements, the authors assign a pivotal role to managers, since its quality depends on the demographic characteristics of the business unit and the effectiveness of the jurisdiction. In this context, the article of Dmour \& Dmour, Abbod [19], which examined the relationship between the qualitative characteristics of financial statements and non-financial business indicators have to be noted. After testing the tightness of this relationship, the authors conclude that taking into account the demographic characteristics of a business unit significantly weakens this tightness [19]. Based on this study, it was concluded that the managers responsible for making decisions in the organization of a business should focus on the essential components of the quality of financial statements (relevance, faithful representation, comprehensibility, and comparability), leveling the importance of demographic characteristics of a business unit.

We should also pay attention to the work of Shalimova, Kuzmenko [20], in which the measurement of the qualitative characteristics of financial statements is carried out concerning such a group as tax relations. Studies emphasize that financial reports should be formed based on the execution of key qualitative characteristics of financial statements, common accounting rules and should be a means of guaranteeing and protecting the interests of all groups of users [20]. However, in their opinion, the financial information needs of such users as tax authorities are ignored, although the exercise of the rights and obligations of a business unit as a taxpayer has a significant impact on users' decisions. The authors substantiate that the need to disclose information about the tax relations of a business unit is a consequence of the application of such a characteristic as relevance, and ignoring such significant information reduces its measurement [20]. It is important to emphasize that the nature of the above studies indicates the commitment of their authors to the Anglo-Saxon accounting system.

The problem of the quality of financial information is also considered by Kolesnikov, Makarov, Safarova [21] in the context of optimizing audit activities, which, in the face of the multiplicity of risks inherent in the external and internal business environment, is aimed not only at creating an effective control system, but also at increasing the quality of accounting in the information system of an economic entity. In their opinion, the solution to this problem lies in the development of a methodology for measuring the effectiveness of the flow of accounting information based on the application of an economic-mathematical model. In the framework of the proposed methodology, the authors suggest a five-point evaluation system, each point is assigned the degree of fulfillment of the qualitative characteristics of the information flow, expressed as a percentage, and a threshold of information usefulness is set at $54 \%$. If it is below, the information is qualified as ineffective [21].

The indicated utility threshold is used by the authors of this article in the proposed methodology for the measurement of the qualitative characteristics of financial statements. All these studies undoubtedly made a significant contribution to the development of the concept of qualitative characteristics of financial statements; however, there exist other works too.

\section{Methodology}

\subsection{Research Methods}

This study was carried out on the basis of general scientific and special methods: a systematic approach, analysis, synthesis, modeling and abstracting, comparison and content analysis. The methodological and theoretical support of the researches undertaken was the official materials (the IFRS Concept, the IFRS, the Directive 2013/34/EU, the legislative and regulatory framework for accounting in the Republic of Moldova), as well as various publications on the problems of financial reporting in scientific journals and their own analytical developments by the authors.

When researching this topic, the authors were guided by the special methods: analysis, in which the features of each primary accounting system (Anglo-Saxon and Continental) were identified, including the qualitative characteristics inherent in each of them; synthesis, using which the conclusions on how qualitative characteristics affect the goals and content of each accounting method are formulated; modeling, with the help of which a methodology for measuring financial statements based on qualitative characteristics is proposed; finally, the comparison method and content analysis applied primarily in terms of the information received from the financial statements, as well as the qualitative characteristics were used concerning accounting methods, based on a reliable representation and regulated accounting. This made it possible to distinguish the third method of accounting and reporting - a mixed one, which clearly showed the failure to adapt two different 
accounting systems in one country, and use of an unequal list of qualitative characteristics.

\subsection{The Requirements of Information Users and Their Qualitative Characteristics}

The attention of modern users of financial statements is aimed not only at understanding the essence of indicators of financial statements, but also on their basis, and business analysis of the organization. In this context, investors are particularly interested in the degree of usefulness of financial statements, and in general, the approach to the formation of qualitative information on the activities of an economic unit. The preparation of the financial statement, qualified as useful, is possible based on an imperative (requirement) of compliance with the concept of qualitative characteristics. General-purpose financial statements cannot contain all the information. However, they provide a significant part of it, on which a group of potential investors and other creditors rely when making management decisions, for example, on the provision of resources to this organization. In the IFRS Concept, this group of users is designated as the main one. Many existing and potential investors, lenders, and other creditors cannot require reporting entities to provide information directly to them. They must rely on general purpose financial statements to obtain a significant part of the financial information they need. Therefore, they are the main users on whom the general purpose financial statements are oriented. Secondarily, financial statements are focused on other groups of users, which may be regulatory authorities and the public [6].

Information addressed to users should be useful to them in order to make effective business decisions. The usefulness of information is determined by its qualitative characteristics. The latest, revised list of qualitative characteristics is contained in the 2018 IFRS Concepts. Moreover, they are divided into two categories, depending on their importance: fundamental and that enhance the usefulness of the information. Fundamental category contains faithful representation and relevance. Faithful representation is of utmost importance because it defines the purpose of accounting. Relevance, which implies its materiality, depends on the nature or quantitative significance of the information, or on both. Other qualitative characteristics only increase the usefulness of information: comparability, verifiability, timeliness, understandability. The IFRS Concept recommends the use of a "rational and effective process for applying qualitative characteristics" [6]. The interconnection of all qualitative characteristics is shown in Figure 1.

The algorithm is based on the identification of economic phenomenon that could potentially be useful to financial statement users. After that, providing that it is accessible to understanding by the user, which will be most relevant and faithfully represented (complete, neutral, and error-free), information is selected. When recognizing information as relevant, there is an emphasis on its materiality. Information is material if it can reasonably be expected that its omission, distortion, or disguise will affect the decisions of the main users of financial statements made on its basis, which provides financial information about a particular reporting organization [22]. If these conditions are met, the information is qualified as useful for making decisions; otherwise, the selection process is repeated.

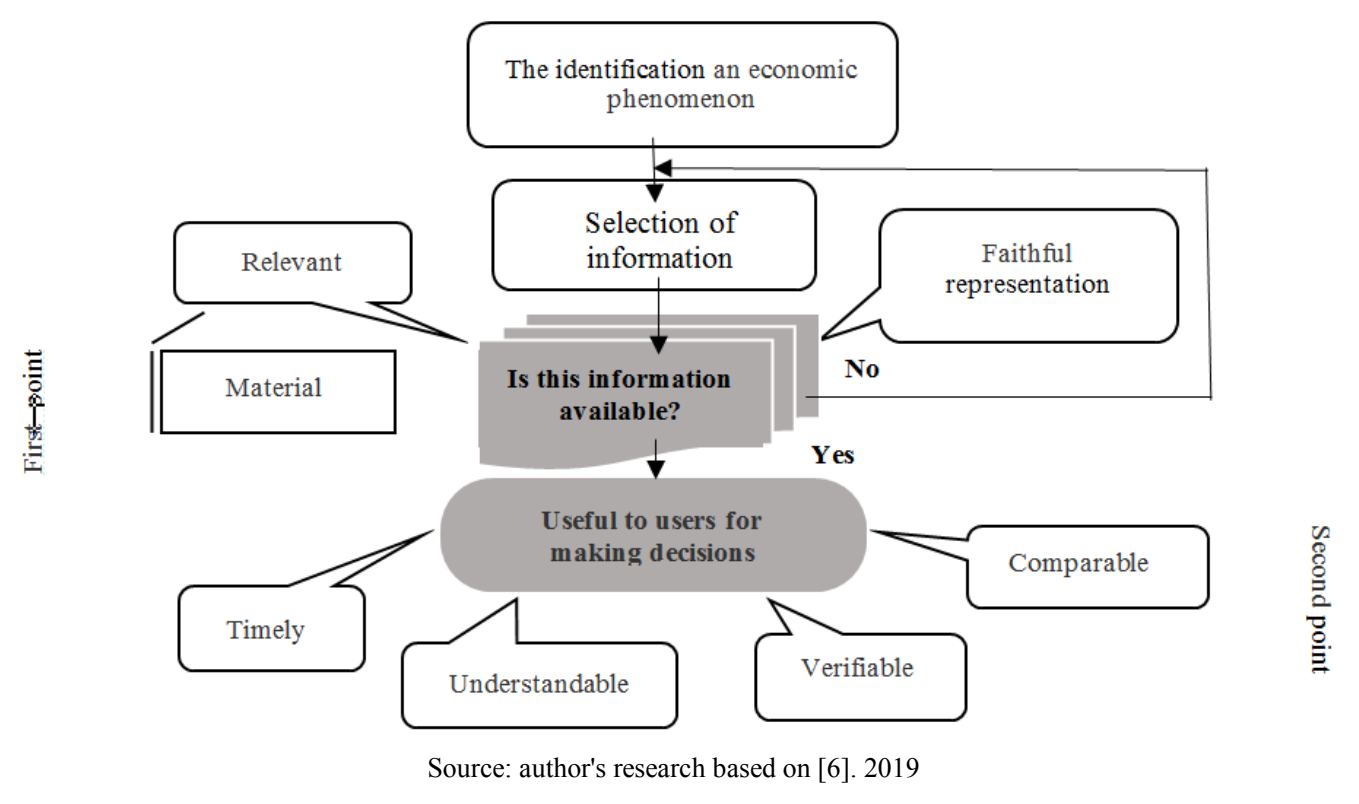

Figure 1. The effectiveness algorithm of the qualitative characteristics of financial statements in accordance with the IFRS Concept.

To achieve optimization of managerial decisions, the compiler of the financial statements must measure such qualities as comparability and verifiability, timeliness, and understandability, the need for which arises in the situation of choosing the measurement method, computation, and accounting procedures. This concludes the process of applying qualitative characteristics in accordance with IFRS, an integral part of which is the application of professional judgment [8].

Based on the preceding, the authors formulate the following thesis: since in the process of measuring the quality of financial information there are two stages of 
establishing utility, there are two degrees of utility: first is when financial information can be useful even if the management decision made on its basis is not sufficiently substantiated, and second is when economic efficiency of decision-making is achieved. This view on the measurement of the usefulness of financial statements is held by Needles, Anderson, Caldwell [23], who believe that useful financial information should have two characteristics - reliability (faithfully representation) and relevance.

\subsection{Measurement Model}

The essence of the proposed methodology for measuring the quality of financial statements is discussed below. Since all qualitative characteristics (useful and enhancing usefulness) in accordance with the IFRS Concept (table 1) are involved in determining the quality of financial information, their share (density in percent) in the overall quality indicator of financial statements is established, depending on the importance of each of them in the formation of information quality. If all the qualitative characteristics are met, then the overall quality score is $100 \%$ of its value is 1.0. Of course, if at least one of it is absent or is not met, the real quality score decreases in comparison with the normative. The calculations will use the following notations of qualitative characteristics: $\alpha$ - usefulness; $\beta$ - that enhance the usefulness. The sequence of calculations is as follows. At the beginning, the usefulness of information is calculated according to formula 1 , while the value of the qualitative characteristics $(\alpha)$ responding to the first degree of usefulness (U') is the same in each accounting system:

$$
\mathrm{U}^{\prime}=\sum_{\mathrm{i}=1}^{\mathrm{n}} \alpha \mathrm{i}
$$

U': Notation of the first degree of usefulness;

$\alpha$ : Notation of fundamental qualitative characteristics;

i: Serial number of qualitative characteristics (for example, $\alpha_{1}$ is the notation of faithful representation);

$\mathrm{n}$ : Quantity of qualitative characteristics.

Then, according to formula 2, the final measurement ( $U^{\prime \prime}$ is the second degree of usefulness) of the characteristics that enhance the usefulness $\left(\mathrm{U}^{\prime \prime}\right)$ is determined:

$$
\mathrm{U}^{\prime \prime}=\sum_{i=1}^{n} \sigma \mathrm{i} \times \beta \mathrm{i}
$$

U": Notation of the second degree of usefulness;

$\sigma$ : Coefficients of qualitative characteristics that enhance the usefulness (for example, $\sigma_{1}$ is the coefficient of comparability);

$\beta$ : Notation of qualitative characteristics that enhance the usefulness (for example $\beta_{1}$ is the notation of comparability).

The measurement of the quality of financial statements (U) is equal to the sum of the indicators of qualitative characteristics of usefulness and that enhance the usefulness of information, calculated according to formula 3 .

$$
\mathrm{U}=\mathrm{U}^{\prime}+\mathrm{U}^{\prime \prime}
$$

U: Notation of usefulness of information for users' decisions.

\section{Results and Discussions}

\subsection{Accounting System in Accordance with IFRS}

The reliability of financial information is provided, first of all, by applying the IFRS Concept, which contains a description of the qualitative characteristics and their application. Moreover, the presence in the IFRS Concept of qualitative characteristics, definitions of various notions, concepts, and other theoretical judgments, distinguish IFRS as a modern accounting methodology. From this point of view, the IFRS Concept is used as a tool for the development of new international standards, changes or cancellation of existing standards, and as a guide in the preparation of national standards by particular countries. IFRS can be used directly in three versions:

1) As the main regulatory documents for a particular country;

2) All enterprises whose shares are listed on the Stock Exchange are required to prepare annual financial statements in accordance with IFRS;

3) Permission by the government of the country to certain types of enterprises to keep accounting and prepare financial statements in accordance with IFRS.

Table 1 below shows a measurement of the qualitative characteristics provided for by the IFRS Concept in

\begin{tabular}{|c|c|c|c|c|c|}
\hline \multirow{2}{*}{ Qualitative characteristics } & \multirow{2}{*}{ Symbol } & \multirow{2}{*}{ Indicator, \% } & \multicolumn{3}{|l|}{ Measurement: } \\
\hline & & & Coefficient $\left(\sigma_{i}\right)$ & $\%$ & rate \\
\hline Faithful representation & $\alpha_{1}$ & 27.0 & $x$ & 27.0 & 0.27 \\
\hline Relevance & $\alpha_{2}$ & 27.0 & \multirow{2}{*}{$x$} & \multirow{2}{*}{27.0} & \multirow{2}{*}{0.27} \\
\hline Materiality & $\alpha_{2}^{\prime}$ & - & & & \\
\hline Usefulness first-degree & $U^{\prime}$ & 54.0 & $x$ & 54.0 & 0.54 \\
\hline Comparability & $\beta_{1}$ & 11.5 & 1.13 & 13.0 & 0.13 \\
\hline Timeliness & $\beta_{3}$ & 11.5 & 0.96 & 12.0 & 0.12 \\
\hline Understandability & $\beta_{4}$ & 11.5 & 0.87 & 10.0 & 0.10 \\
\hline Usefulness second-degree & $\mathrm{U}^{\prime \prime}$ & 46.0 & $\times$ & 46.0 & 0.46 \\
\hline Usefulness of information for users' decisions & $\mathrm{U}$ & 100 & $x$ & 100 & 1.00 \\
\hline
\end{tabular}
accordance with the methodology proposed by the authors.

Table 1. Measurement of financial information in accordance with the IFRS Concept.

Source: developed by the authors. 2019 
It is easy to see that in such business units if all the qualitative characteristics contained in the IFRS Concept and International Accounting Standard (IAS) 1 "Presentation of Financial Statements" are applied, the measurement of the representation of financial information in financial statements is optimal, i.e., at a rate of $100 \%$ or equal to 1.0 .

Nevertheless, in the context of the establishment of the concept of qualitative characteristics in the IFRS system, questions for further discussion arose, and many critical views were expressed. Let us consider some of them. As already noted, in the IFRS Concept, the qualitative characteristics are divided into fundamental and that enhance the usefulness of information, which, according to the authors, is not wholly successful. A well-known fact is that the classification is based on one characteristic, but not on various; therefore, as applied to qualitative characteristics, if the basis for the division is the contribution to the usefulness of information, then one group is designated as fundamental characteristics.

The second group should be classified as auxiliary characteristics. This point of view is shared by Tsygankov and Fadeykina [1], who believe that groups should be designated as the main and auxiliary characteristics. Another object of criticism was their ranking in the IFRS system. According to Tsygankov and Fadeykina, financial reporting is not always appropriate, not for everyone, not in any circumstances, but only for existing and potential investors, creditors when they make investment decisions regarding resources [1]. They adhere to the position of the editors of IFRS Concept, the year 1989, and consider clarity to be the most important characteristic, since, in their opinion, only understandable information can be relevant and, as a result, useful. However, we cannot disagree with the opinion of Hendriksen and van Breda [24], which emphasize that "the type of user is a key factor in decisions about what information to present since the perception of information depends on the users' quality". In this regard, it is appropriate to note that, with the innovative vector of the economy, the accounting and financial reporting methodology is focused on its compilers, having competencies in understanding business and economic activities, and is created for users who possess skills to prepare reports and the ability to study and analyze the information. At the same time, it is clear that even well-informed users may have questions in terms of understanding the complex economic phenomena information. The above argues the author's position, which is consistent with the ranking of the qualitative characteristics of the 2018 IFRS Concept [6].

The next object of criticism is the measurement uncertainty. According to the IFRS Concept, it is a new attribute, as a factor restricting the faithful representation, and indicating a compromise between the degree of measurement uncertainty and other properties that ensure the faithfulness of the information. Faithful representation does not mean accuracy in all respects. The absence of errors does not imply accuracy but means that there are no errors or omissions in the description of the economic phenomenon, and the process used to obtain the presented information was selected and applied without errors [6]. In this context, Kruglyak and Shvyreva [3] believe that since the uncertainty in the measurement affects the numerical display of reporting indicators, this factor limits both the relevance and faithful representation of information, and, as a result, its usefulness in general. In their opinion, new term prudence, a sub characteristic of truthful representation, which should correspond to a conservative approach in terms of recognition of income and expenses, should be introduced. However, they ignored an essential aspect of the preparation of financial statements in the IFRS system, i.e., impairment testing, which is considered a new version of the principle of prudence, which, from the point of view of the author of the study, neutralizes the above criticism.

According to the results of the study, the authors of the article conclude: in the IFRS system, a concept of qualitative characteristics is formed as an imperative for the preparation of useful information in financial statements. The proposed conclusion corresponds to the opinion of Plakhtiy [25], who substantiates her point of view on the concept of qualitative characteristics of information through the prism of its historical development and formation. Tsurcanu [8] adheres to the conceptual approach concerning qualitative characteristics, treating them as one of the factors that form the concept of the reliability of financial statements.

\subsection{Accounting System in Accordance with the EU Directive}

European Union countries are required to keep records and reports in accordance with European Directive (Directive 2013/34/EU). It also contains qualitative characteristics of information that are mandatory for use by economic entities of EU member countries (table 2). As can be seen, there are three main qualitative characteristics: reliability, materiality, and objectivity, the fact that distinguishes them from the functional ones contained in the IFRS Concept. Furthermore, since materiality is not an independent characteristic, according to Directive $2013 / 34 / E U$, it is assigned only a value of $10 \%$, without any coefficient. This is due to compliance with the measurement methodology, in which in all systems, there are only two basic (fundamental) qualitative characteristics. Objectivity implies relevance: if the information is represented objectively, then it is relevant. Table 2 below shows the measurement of the qualitative characteristics provided for by Directive 2013/34/EU according to the methodology proposed by the authors. 
Table 2. Measurement of financial information in accordance with the Directive 2013/34/EU.

\begin{tabular}{|c|c|c|c|c|c|}
\hline \multirow{2}{*}{ Qualitative characteristics } & \multirow{2}{*}{ Symbol } & \multirow{2}{*}{ Indicator, $\%$} & \multicolumn{3}{|l|}{ Measurement: } \\
\hline & & & Coefficient $\left(\sigma_{i}\right)$ & $\%$ & rate \\
\hline Reliability & $\alpha_{1}$ & 22.0 & 1.23 & 27 & 0.27 \\
\hline Materiality & $\alpha_{2}^{\prime}$ & 10.0 & 0 & 0 & 0 \\
\hline Objectivity & $\alpha_{3}$ & 22.0 & 1.23 & 27 & 0.27 \\
\hline Usefulness first-degree & $U^{\prime}$ & 54.0 & $\times$ & 54 & 0.54 \\
\hline Comparability & $\beta_{1}$ & 23.0 & 1.0 & 23 & 0.23 \\
\hline Understandability & $\beta_{4}$ & 23.0 & 1.0 & 23 & 0.23 \\
\hline Usefulness second-degree & $U^{\prime \prime}$ & 46.0 & $\times$ & 46 & 0.46 \\
\hline Usefulness of information for users' decisions & $\mathrm{U}$ & 100 & $x$ & 100 & 1.00 \\
\hline
\end{tabular}

Source: developed by the authors. 2019

As can be seen from table 2, in Directive 2013/34/EU, the list of qualitative characteristics is much smaller than in the IFRS Concept. This is determined by accounting systems: the first, according to IFRS, is more liberal, advisory, based mainly on principles and qualitative characteristics. The second is prescriptive and is based on the legal representation of information; therefore, the list of qualitative characteristics is narrowed to four. However, in the Directive, 2013/34/EU "usefulness" is designated as "equivalence".

\subsection{Accounting in Associated Countries with the EU}

In many countries, the transition to a market economy has developed national accounting regulatory documents focused on IFRS. Thus, in the Republic of Moldova in 1997 Conception of Accounting Reform, it was indicated that National Accounting Standards (NAS) were developed based on IFRS [26]. It means that they should have been consistent with IFRS. In fact, their content was far from the IFRS regulations. Subsequently, due to the absence of many positions in national standards, the country's regulatory authorities recommended enterprises to use the regulations of the relevant IFRS. However, the applied qualitative characteristics were contained either in the Accounting Law [27] or in other regulatory acts on accounting, which led to a miscellaneous in the applied qualitative characteristics at different enterprises. The calculations showed that, in comparison with IFRS (on the relevant date), the coefficient for measuring the quality of financial reports of Moldovan enterprises using NAS is as follows:

1) In $1997-0.78$, qualitative characteristics were taken from the Concept of Accounting Reform of the Republic of Moldova for that year [26];

2) In $2007-0.83$, qualitative characteristics were taken from the Accounting Law, 2007 [27];

3) In $2013-0.87$, qualitative characteristics were selected according to NAS, 2013 [28].

As can be seen for all periods, the ratio is below 1.0, that is, the reliability of the financial statements in Moldova did not reach the normative level stipulated by IFRS. This suggests that some qualitative characteristics were not observed, especially comparability.

In 2015, the Ministry of Finance of the Republic of Moldova began to work on transferring the regulations of the Directive 2013/34/EU into its accounting legislation until 2018. Thus, changes to the Accounting Law and NAS were made. In the Directive state that "as a result of transposition, each country that is a partner in the agreement with the EU may have individual qualitative characteristics, partially taken from IFRS Concepts and partially from Directive 2013/34/EU" [29]. However, how to combine two different in their purpose concepts of faithfulness and directivity in one accounting system?

In the RM, accounting, after approaching Directive 2013/34/EU and continuing to follow the principles of IFRS, remains a strictly regulated accounting system, the contents of which are difficult to be understood by specialists, because when applying IFRS, the preparation of financial statements is carried out according to the economic approach, which is based on the concept of a "truthful and faithful representation" and Directive 2013/34/EU contains specific requirements (legal approach) based on the concept of "directivity and clarity". In this context, the authors support the opinion of Grigoroy and Muntean [30] that to understand the scientific approach in terms of harmonizing the accounting system; it is necessary to study all aspects of the modern accounting methodology - the IFRS methodology. Since the legislative framework is designed to embody the current methodology, we will stop on the regulations of the legislative and regulatory framework governing the application of qualitative characteristics within the international system and practice of accounting and financial reporting in the RM. For this purpose, the table discloses the composition of qualitative characteristics and concepts that underlie accounting systems and financial reporting.

As already known, in the system of international standardization, the IFRS Concept defines a system of qualitative characteristics as an imperative for the reliability of financial statements, which is indicated by the regulations of IAS 1 "Presentation of Financial Statements" [5]. Within the framework of the continental accounting system, the requirements for the quality of the information in financial statements are outlined in Directive 2013/34/EU. In the Republic of Moldova, Law No. 287 (in order to recognize financial statements as clear) requires compliance of the fundamental principles and qualitative characteristics of information, regardless of the adopted model of financial statements [29, art. 20]. The legislative framework, which clearly establishes the requirement to comply with the quality of financial reporting information, also defines the qualitative characteristic system as imperative. 
Based on a comparative analysis of the data in Table 3 , it becomes evident that the legislative framework of the RM accumulates the regulations of both the IFRS system and
Directive 2013/34/EU, which are designed to regulate two different accounting models - Anglo-Saxon and Continental.

Table 3. Comparison of the system qualitative characteristics of the financial statements.

\begin{tabular}{llll}
\hline Indicators & Conceptual Framework IFRS & Directive 2013/34/UE & Law No. 287 RM \\
\hline Presentation concept & Faithfulness and Fairness & Directivity and Clarity \\
Assigning concept & Usefulness & Reliability and Objectivity \\
Fundamental characteristics & Faithful representation & Reliability & Directivity and Clarity \\
& Relevance & Objectivity & Materiality \\
Subcharacteristic & Materiality & Comparable* & Relevance \\
Characteristics that enhance the & Comparable and Verifiable & Equivalence* & Comparable and Verifiable \\
usefulness/reliability* of information & Timely and Understandable & & Timely and Understandable \\
\hline
\end{tabular}

Source: developed by the authors on the basis of: [6, 7, 29]. 2019

So, adhering to the legal approach of presenting financial statements, which is enshrined in the indicated concept (Table 3), Law No. 287 relates the fundamental qualities of information as relevance, compliance with which is necessary as part of the economic approach, while the second fundamental quality is the accuracy of the representation, which in turn contradicts the concept of faithfulness and justice (economic approach). In this context, the requirement to comply with such a feature that enhances usefulness as verifiability becomes unclear, because undoubtedly, if the information is accurate in the estimates, then it was subject to verification. It is worth noting that the quality system of Directive 2013/34/EU ignores this characteristic.

It is important to note that in accordance with Law No. 287 of the Republic of Moldova, any enterprise that conducts accounting following the NAS may, if necessary, switch to IFRS [29]. In this case, we should also consider the legal side, in which all enterprises operating on the territory of the RM must comply with this law, prepared in accordance with the European Directive. However, any business unit that will use the NAS will consider that it is guided by this methodology, not directly, but indirectly.

However, in this case, it is necessary to clarify the essence of qualification characteristics, exceptionally fundamental, so that they do not contradict the IFRS Concept. It is controversial to include the accuracy of representation among useful qualitative characteristics. Article 15 of the IFRS Concept emphasizes that "faithful representation does not mean accuracy in all respects" [6], and, conversely, accuracy does not mean faithful representation; along with neutrality and full representation of information, it forms three characteristics of the faithfulness of information. Moreover, in this context, the IFRS Concept focuses not on the accuracy, but on the absence of errors in describing an economic phenomenon.

There is some bewilderment of such a qualification group of qualitative characteristics, indicated in Law No. 287, as increasing the usefulness of information focused on decisionmaking by management, if the concept of assigning financial statements in the accounting and reporting system of the Republic of Moldova is an accuracy of representation aimed at such a group of users as the tax authorities.

Thus, the authors argue on hypothesis $\mathrm{H} 1$ : in the accounting methodology of the Republic of Moldova, there is no conceptual space for applying qualitative characteristics that would meet the requirement of the reliability of financial statements.

To prove the revealed contradiction, we will evaluate the qualitative characteristics of the financial statements based on the methodology proposed above. This calculation will serve as a justification for the hypothesis H2. Thus, for business units that use IFRS, the qualitative characteristics remain in accordance with the IFRS Concept, for those who use the National Accounting Standards, the list of quality characteristics is presented in accordance with Law No. 387 (table 4).

Table 4. Measurement of the financial information in accordance with the regulatory framework of accounting system of the RM.

\begin{tabular}{|c|c|c|c|c|c|}
\hline \multirow{2}{*}{ Qualitative characteristics } & \multirow{2}{*}{ Symbol } & \multirow{2}{*}{ IFRS } & \multirow{2}{*}{ Directive 2013/34/UE } & \multicolumn{2}{|c|}{ Law No. 287 RM } \\
\hline & & & & rate & $\%$ \\
\hline Faithful representation & $\alpha_{1}$ & 0.27 & 0.27 & 0.27 & 27.0 \\
\hline Relevance & $\alpha_{2}$ & \multirow{2}{*}{0.27} & $\times$ & 0.27 & 27.0 \\
\hline Materiality & $\alpha_{2}^{\prime}$ & & 0 & $\times$ & $\times$ \\
\hline Objectivity & $\alpha_{3}$ & $\times$ & 0.27 & $\times$ & $\times$ \\
\hline Usefulness first-degree & $\mathrm{U}^{\prime}$ & 0.54 & 0.54 & 0.54 & 54.0 \\
\hline Comparability & $\beta_{1}$ & 0.13 & 0.23 & 0.23 & 23.0 \\
\hline Timeliness & $\beta_{3}$ & 0.12 & $\times$ & 0.12 & 12.0 \\
\hline Understandability & $\beta_{4}$ & 0.10 & 0.23 & 0.23 & 23.0 \\
\hline Usefulness second-degree & $\mathrm{U}^{\prime \prime}$ & 0.46 & 0.46 & 0.69 & 69.0 \\
\hline Usefulness of information for users' decisions & $\mathrm{U}$ & 1.00 & 1.00 & 1.23 & 123 \\
\hline
\end{tabular}

Source: developed by the authors. 2019 
According to the results of the 2019 study limit indicator of qualitative characteristics is 1.0 . The excess in table 4 of this level by 0.23 points is caused by the combination of two systems into one in Moldova. The obtained results prove that the accounting system existing in the Republic of Moldova does not contain an effective model for measuring the information of financial statements based on qualitative characteristics since some of them are contradictory (hypothesis $\mathrm{H} 2$ ).

We cannot disagree with the opinion by Grigoroy and Muntean [30] that Law No. 287 RM not only did not resolve several controversial issues that reduced the effectiveness of the previous Accounting Law but created confusion regarding its application in practice, since the NAS mainly based on IFRS and do not clearly reflect the contribution of European Directives. Moreover, it does not meet the requirement of the model of an innovative economy: the transition from traditional accounting to knowledge-based accounting. In conclusion, it should be noted that the IFRS Concept is changing, modernizing, and introducing adjustments in general to IFRS, which leads to the need to adapt the legislative and regulatory framework of the Republic of Moldova to the new IFRS. This process is quite creative, especially in conditions where adequate transposition of the regulations of Directive 2013/34/EU is required.

\section{Conclusions}

At the present stage of business development, the quality of financial information presented in the financial statements is crucial in making the right economic decisions. It is necessary both for the compilers of the reports and its users. As a result of studying the essence and methodological aspect of qualitative characteristics, on their basis the authors proposed a methodology for assessing financial statements. To achieve this goal, the study: (1) found a successful separation in Concept IFRS of qualitative characteristics into fundamental ones (determining the usefulness of information) and that enhance its usefulness, which created the prerequisites for developing a methodology for measuring the quality of financial statements; (2) it has been established that in two main accounting systems: AngloSaxon, which is the basis of IFRS and continental, the basis of which are EU Directives, the concepts and the list of qualitative characteristics differ; (3) it is argued that differences in the concepts of qualitative characteristics in these accounting systems do not significantly affect the purpose of the study - the development on their basis of a unified model for assessing the usefulness of information; (4) the values of each of the qualitative characteristics and the coefficients of the characteristics that enhance the usefulness of the information are determined. On this basis, formulas are proposed for calculating the indicator of measuring the quality of the financial statements of an enterprise for each level of its utility, which are adaptable to any accounting system and regardless of industry. The overall conclusion of the study is as follows: in the countries associated with the EU, a third (mixed) accounting system based on the convergence of the two main systems was formed, and their accounting and reporting contain the requirements of both IFRS and Directive 2013/34/EU.

In these conditions, it is necessary to develop a unified concept of the qualitative characteristics of financial statements, which is proved by the results of the implementation of the proposed methodology for measuring the quality of information. The consequences of such a combination without an effective conceptual platform in national accounting systems as a whole are demonstrated by the authors on the example of the Republic of Moldova. In this context, it is important to continue work on harmonization of accounting systems, which will contribute to the maximum approximation of all its elements, including qualitative characteristics and financial statements. This approach contributed to the substantiation of the hypotheses put forward by the authors on this study, but also to their proof not only in terms of the theoretical significance of the qualitative characteristics of financial information but also their practical application.

\section{References}

[1] Tsygankov, Kim, Fadeikina, Natalia. Conceptual Bases of Financial Statements: Qualitative Characteristics// Finance and Accounting, 2016, No. 4, pp. 98-105, retrieved from: http://elibrary_2673279458.pdf.

[2] Achim, Andra M., Chish, Anca, O. Financial accounting quality and its defining characteristics/Practical Application of Science, 2014, vol. II, iss. 3 (5), pp. 93-98, retrieved from: https://seaopenresearch.eu/SPAS_5_13.

[3] Kruglyak, Zinaida, Shvyreva, Olga. Development the System of Qualitative Characteristics of Financial Information //International Accounting, 2017, Vol. 20. Iss. 18. pp. 10511065, retrieved from: http://doi.org/10.24891/ia.2018/1051.

[4] Tabara, Neculae. Comparative accounting systems, edition of $\Pi$ revised and supllemented. Iasi, 2014, Tipo Moldova Publishing House.

[5] International Accounting Standard 1 «Presentation of Financial Statements», retrieved fromhttp://ec.europa.eu/docs/arc/ias1_ann.

[6] Conceptual Framework for Financial Reporting [online], retrieved from: http://www.ctcp.gov.co/_files/documents.

[7] Directive 2013/34/EU of European Parliament and of the Council of 26 June 2013 'On the annual financial statements, consolidated financial statements and related reports of certain types of undertakings', retrieved from: http://eurlex.europa.eu/LexUriServ $\backslash$.

[8] Tsurcanu, Viorel, Golochalova, Irina. Accounting truth and its assurance in entities from the Republic of Moldova, Audit Financial, vol. XIV, no. 7 (139)/2016, pp. 769-780, retrieved from: https://revista.cafr.ro/RevistaDetalii_EN ?Cod=1070, DOI: 10.20869/AUDITF/2016/139/769. 
[9] Feleaga, Neculae. Comparative accounting systems, edition of П, a vol. П - International accounting standards. 1999, Economic Publishing House.

[10] Pyatov, Mikhail, Smirnova, Irina. Conceptual Framework of International Accounting Financial Reporting, 2008, «1cPublishing» Publishing House.

[11] Colasse, Bernard. Basic of Accounting (translated N. Tabara). Iasi, 2009, Publish. Tipo Moldova.

[12] Alexander, David, Britton, Anne, Iorisen, Enn. International Financial Reporting Standards: from theory to practice, Moscow, 2005, Vershina Publishing House.

[13] Sokolov, Yaroslav, Terentyeva, Tatyana. Accounting and Auditing: Modern Theory and Practice, St. Petersburg, 2009, Economy Publishing House.

[14] Alekseev, M., Glinskiy, V., Serga, L., Pyatov, M. On Evaluating Likely Misstatements in Financial Statements of Economic Entities. Issues Statistics, 2019, 26 (7), pp. 20-32, retrieved from: https://voprstat.elpub.ru/jour/article/view/934, https://doi.org/10.34023/2313-6383-2019-26-7-20-32.

[15] Tsurcanu, Viorel, Golochalova, Irina. Accounting in Republic of Moldova between IFRS and EU Directives. Collection of Articles Selective, Vol. 4, of 23-24 September 2016, Publishing House ASEM, pp. 200-206, retrieved from: https://ase.md/publicatii-electronice.html.

[16] Richard, Jacques. Accounting: Theory and Practice. Moscow, 2000: Finance and Statistics.

[17] Beest van Ferdy, Braam, Geert, Boelens, Susanne. Quality of Financial Reporting: measuring qualitative characteristics, 2009, retrieved from: http://www.ru.nl/nice/workinqpapers.

[18] Nobes, Christofer, W., Stadler, Chistian. The Qualitative Characteristics of Financial Information, and Managers' Accounting Decisions: Evidence from IFRS Policy Changes, 2015, retrieved from: https://doi.org/10.1080/00014788.2015.1044495.

[19] Dmour, Ahmad, Dmour, Hani, Abbod, Maysam, F. Qualitative Characteristics of Financial Reporting and Non-Financial Business Performance, 2017, retrieved from: https://www.researchgate.net/publication/324494814_, DOI/10.4018/IJCFA.2017070101.

[20] Shalimova, Nataliia, Kuzmenko, Halyna. Information Transparency of the Activity of the Enterprise as Taxpayer:
Science Review. Economy 1 (8), Vol. 4, January 2018, retrieved from: https://www.academia.edu/37855386/.

[21] Kolesnikov, V., Makarov, I., Safarova, A. Economic and Mathematical Modeling of the Audit Assessment of the Effectiveness of Accounting Information, 2017, retrieved from: https:/cyberleninka.ru/article/n/economiko-matematicheskoe

[22] Amendments to IAS 1 and IAS 8. "Definition of Material" retrieved from: http://www.iasplus.com/en/news/2018/10/definition-ofmaterial.

[23] Needles, Belverd, E., Anderson, Henry, R., Caldwell, James, C. Principles of Accounting, Moscow, 1999: Finance and Statistics.

[24] Hendriksen, Eldon S., van Breda, Michael F. Accounting Theory. - Moscow, 2000: Finance and statistics.

[25] Plakhtiy, Tatyana. Historical Analysis of Development of Concept of Qualitative Characteristics of Accounting Information//Accounting and Finance, 2016, No. 4, pp. 60-68, retrieved from: http://www.afj.org.ua/ru/article/428/.

[26] Conception of reform of the Accounting, Government Degree No. 1187 of December 24, 1997 RM, retrieved from http://lex.justice.md/document_rom.php?id.

[27] Law No. 113-XVI of April 27, 2007, of the Republic of Moldova „On Accounting”, retrieved from http://lex.justice.md/viewdoc.php?action=view\&view=doc\&id $=351443$ \&lang $2=1$.

[28] National Accounting Standards "Presentation of Financial Statements", approved by Order of the Ministry of Finance No. 118 from August 06, 2013, with modification 01.01.2019, retrieved from: http://www.old.mf.gov.md/actnorm//contabil/stantard/new.

[29] Law No. 287 of December 15, 2017 of the Republic of Moldova, On Accounting and Financial Reporting", retrieved from http://lex.justice.md/viewdoc.php?action=view\&view=doc\&id=3 63701\&lang2.

[30] Grigoroy, Lilia, Muntean, Neli. The Innovative Experience of the Republic of Moldova in Reforming the Accounting System and its Harmonization with IFRS and European Directives. Marketing and Management of Innovations, 2019, Issue 1, retrieved from: http://doi.org/10.21272/mmi.2019.127. 